Diabetologia, Suppl. to $9,317-319(1973)$

(C) by Springer-Verlag 1973

\title{
Unaltered Glucagon Secretion after Seven Days of Sulphonylurea Administration in Normal Subjects*
}

\author{
J. Mareo and I. Valverde \\ Clinica Puerta de Hierro and Fundación Jiménez-Díaz, Universidad Autónoma de Madrid, Madrid
}

Received: April 5, 1973, and in revised form: June 21, 1973, accepted: June 27, 1973

Summary. The effects of the chronic administration of sulphonylureas on glucagon secretion were studied in two groups of normal volunteers. One group $(n=7)$ received glipizide, $10 \mathrm{mg}$ daily, in a single dose, for seven days. The other group $(n=6)$ received glibenclamide under the same conditions. Basal glucagon and insulin levels and the response of these hormones to an arginine stimulus were studied before and after the sulphonylurea course. - After treatment, neither the basal glucagon values nor the arginine-induced glucagon secretion was significantly altered when compared to the control experiments. The insulin curves showed great variability, being increased in some cases and decreased in others. The mean results showed no significant change in the insulin secretion pattern after sulphonylurea administration. - Our data do not lend support to the hypothetical action of sulphonylureas through the alpha cell.

Key words: Glucagon, insulin, glucose, arginine, sulphonylurea, glipizide, glibenclamide, normal subjects.
Although the insulin-secreting capacity of the sulphonylurea compounds is accepted, it still remains to be settled whether the antidiabetic effect of the longterm administration of these drugs is solely due to their ability to stimulate the beta cell. Indeed, several investigators have reported a diminished insulin response to various stimuli after chronic sulphonylurea administration in man as well as in laboratory animals $[1,2,3,4]$. This topic has been reviewed by Feldman and Lebovitz [5].

In 1969 Samols and associates [6], working with an animal model (Peking ducks), humans, and isolated rat pancreas described a glucagon-lowering effect of tolbutamide, an action which would obviously be an important factor in explaining the hypoglycaemic effect of the sulphonylureas. In the present work we have studied the effects of a seven-day course of treatment with glipizide (a new and potent sulphonylurea) [7] and with glibenclamide on basal glucagon levels and on the secretory response of the alpha cell to an arginine challenge in two different groups of normal subjects. It was found that neither glipizide nor glibenclamide significantly affected the secretion of glucagon.

\section{Materials and Methods}

Young, healthy, non-obese volunteers of both sexes, with no clinical history of diabetes in their families, were selected for our study. All were students at the Universidad Autónoma de Madrid and had been informed of the purpose and nature of the experiments.

* Presented at the Eighth Annual Meeting of the European Association for the Study of Diabetes, September 7,1972 , Madrid, Spain.

This work has been in part supported by I.N.P. grant 12.071-72.
Volunteers had been instructed to follow a diet containing at least $250 \mathrm{~g}$ of carbohydrates daily for three days before the start of the experiments and during the period of sulphonylurea treatment. One group of seven subjects was given glipizide (N-4-[ $\beta$-(5-Methylpyrazine-2-carboxamido) - ethyl - benzene - sulphonyl $\mathrm{N}^{\prime}$-cyclohexyl-urea) in a single dose of $10 \mathrm{mg}$ daily before the mid-day meal. The second group, of six subjects, was given glibenclamide at the same dose level ${ }^{1}$. The drug regimen was followed for seven days. Each individual served as his own control.

Volunteers reported to the laboratory between $9: 00$ and 10:00 a.m. after an overnight fast. Tests were carried out with the subjects in a recumbent position. For sampling, an indwelling butterfly needle connected to a stopcock was placed in an antecubital vein and kept patent with a $0.1 \%$ heparin solution. In the other arm, a similar set-up was applied for the administration of the arginine load. Arginine monohydrochloride in a $20 \%$ solution (Arginina, Hermes), was injected as a dose of $468 \mathrm{mg}$ per $\mathrm{kg}$ of body weight over a ten-minute period. The subjects were allowed to relax for twenty minutes before collection of the first control sample.

Blood samples $(10 \mathrm{ml})$ were drawn at ten-minute intervals throughout the test. For glucose and insulin measurements, $5 \mathrm{ml}$ of blood were placed in chilled tubes containing EDTA; another $5 \mathrm{ml}$ for glucagon analysis were collected in chilled tubes containing EDTA and $2500 \mathrm{U}$ of kallikrein-trypsin inhibitor (Trasylol, Bayer) in a volume of $0.5 \mathrm{ml}$. The blood was promptly centrifuged at $4^{\circ} \mathrm{C}$, and the plasma was stored at $-20^{\circ} \mathrm{C}$ until the time of assay. Assays were performed within two weeks of the date of the experiments. All samples were tested in duplicate. Plasma

1 The drugs used in this study were kindly supplied by Dr. M. Usano, Pfizer, Spain. 
glucose was determined by means of a commercial glucose-oxidase preparation (Biochemica Test Combination, Boehringer Mannheim GmbH). Insulin was measured by radioimmunoassay using a charcoal separation method [8]. Glucagon was assayed radioimmunologically [9] with an antiserum (30K) highly specific for pancreatic glucagon (kindly supplied by Dr. Roger $\mathbf{H}$. Unger). Our glucagon analysis allows measurement of $25 \mathrm{pg} / \mathrm{ml}$ above zero with $95 \%$ confidence and we have been able to detect a decline of 37 picogram $/ \mathrm{ml}$ from the basal values in other studies $[10]$.

Statistical processing of the data was performed by conventional methods.

\section{Results}

Glipizide-Treated Group. In Fig. 1 are represented the mean glucagon, insulin and glucose curves for the group of subjects treated with glipizide.

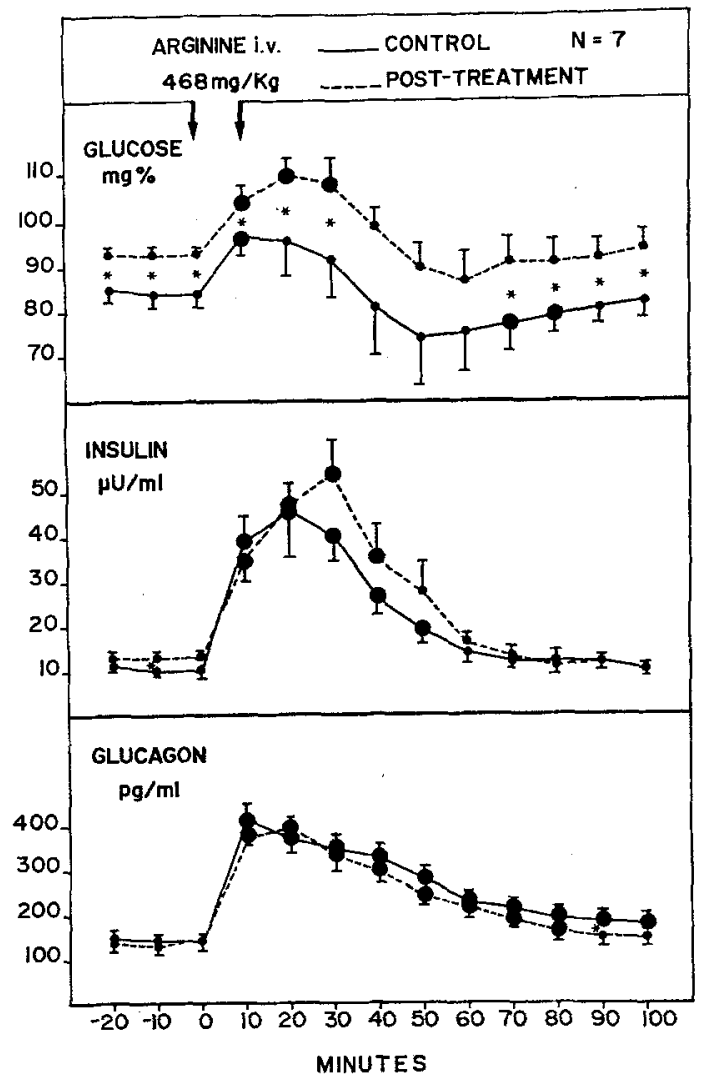

Fig. 1. Effect of glipizide pretreatment $(10 \mathrm{mg}$ daily, for seven days) on the arginine-induced glucagon secretion in normal subjects. The large circles represent statistically significant differences from the baseline. The asterisks represent statistically significant differences between control and post-treatment values at a given time. (Mean 1 S.E.M.)

After treatment, neither the basal glucagon values nor the arginine-induced glucagon secretion was significantly altered when compared to the control experi- ments. The sample taken at $90 \mathrm{~min}$ showed a difference $(34 \mathrm{pg} / \mathrm{ml})$ with a $P$ value of less than $0.05 \mathrm{but}$, since this was the only point of the thirteen studied in which a statistically significant difference could be detected, we regard it as a random finding.

With the exception of a $3 \mu \mathrm{U} / \mathrm{ml}$ change $(P<0.005)$ above control at the $-10 \mathrm{~min}$ baseline point, there is no significant difference between the pre and posttreatment insulin curves.

After treatment with glipizide, the entire glucose curve lay above the control values; the differences being significant in the three baseline points $(P<0.01)$, at 10,20 , and $30 \mathrm{~min}(P<0.05)$, and at $70,80,90$, and $100 \min (P<0.001)$.

Glibenclamide-Treated Group. In this group, (Fig. 2) as in the preceeding one, the pre and post-treatment glucagon levels before and after the arginine load overlapped. The plasma insulin concentrations were not significantly affected by glibenclamide pretreatment. Although, as in the glipizide experiments, the

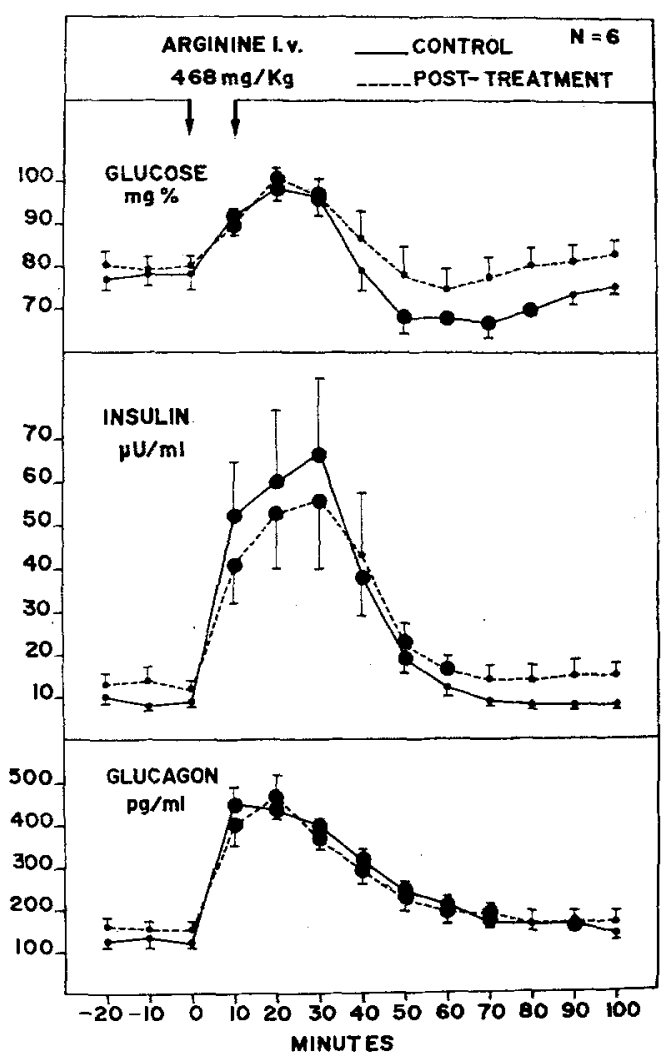

Fig. 2. Effect of glibenclamide pretreatment $10 \mathrm{mg}$ daily, for seven days) on the arginine-induced glucagon secretion in normal subjects. The large circles represent statistically significant differences from the baseline. (Mean \pm S.E.M.)

post-treatment glucose curve was elevated above the control, the elevation was less marked and without statistical significance. 


\section{Discussion}

In an attempt to simulate the true clinical situation in which the patient continues sulphonylurea treatment over a long period of time, we have employed a seven-day course of administration of the drugs rather than giving an isolated dose.

The data here reported show that neither glipizide nor glibenclamide has any influence on basal glucagon levels and alpha cell responsiveness to arginine in normal subjects. This does not support the concept that the sulphonylureas might, in part, exert their hypoglycaemic effect via the alpha cell. Likewise, Pek et al. [11] were unable to demonstrate any significant modification of basal glucagon levels and amino acid. induced glucagon secretion after i. $\nabla$. tolbutamide or oral chlorpropamide in healthy volunteers. Similar results were obtained by Aguilar-Parada et al. [12] injecting one dose of glibenclamide in dogs. Buchanan et al. in isolated rat pancreatic islets [13] and Chesney and Schofield in mouse islets [14] also failed to demonstrate any change in the secretion of glucagon with tolbutamide. Contrary to these "in vitro" studies, Laube et al. [15], working in perfused rat pancreas, and. Iversen [16], working in perfused canine pancreas, have reported an inhibitory effect of tolbutamide on glucagon release. However, our results do not exclude the possibility that sulphonylureas could induce a reduction of the hyperglucagonaemia seen in diabetics [9], as a consequence of the amelioration of the disturbed metabolic state.

Concerning insulin secretion, there was no obvious difference between the pre and the post-treatment mean curves with either of the two sulphonylureas tested. There was great variability in the response to arginine; in some cases there was a slight increase and in others, a frank decrease. The latter finding could be due to a relative exhaustion of the beta cell occurring in normal subjects after over-stimulation with these drugs. A consequence of this exhaustion of the beta cell would be an elevation of the glycaemia. This hyperglycaemia would, in turn, further stimulate insulin secretion, the net effect of which would be a normalization of insulin levels.

Acknowledgements. Thanks are indebted to Ms. Inés García-Muñoz for expert technical assistance.

\section{References}

1. Reaven, G., Dray, J.: Effect of chlorpropamide on serum glucose and immunoreactive insulin concentrations in patients with maturity-onset diabetes mellitus. Diabetes 16, 487-492 (1967)
2. Seltzer, H.S., Allen, E.W., Brennan, M.T.: Failure of prolonged sulfonylurea administration to enhance insulinogenic response to glycemic stimulus. Diabetes $14,392-395(1965)$

3. Salans, L.B., Reaven, G.M. : Effect of oral hypoglycemic agents on serum insulin-like activity of patients with various degrees of carbohydrate intolerance. Metabolism 14, 26-30 (1965)

4. Sussman, K. E., Stjernholm, M., Vaughan, G.D.: Tolbutamide and its effect upon insulin secretion in the isolated perfused rat pancreas. In "Tolbutamide. . . after ten years", pp. 22-33. Amsterdam: Excerpta Medica Foundation 1967

5. Feldman, J.M., Lebovitz, H.E.: Appraisal of the extrapancreatic actions of sulfonylureas. Arch. int. Med. 123, 314-322 (1969)

6. Samols, E., Tyler, J., Mialhe, P.: Suppression of pancreatic glucagon release by the hypoglycaemic sulfonylureas. Lancet 1969 I, 174-176

7. Ambrogi, V., Bloch, K., Daturi, S., Griggi, P., Logemann, W., Parenti, M. A., Rabini, T., Tommasini, R.: New oral antidiabetic drugs. Part I. ArzneimittelForsch. 21, 200-204 (1971)

8. Herbert, V., Lau, K., Gottlieb, C.W., Bleicher, S.J.: Coated charcoal immunoassay of insulin. J. clin. Endocr. 25, 1375-1384 (1965)

9. Aguilar-Parada, E., Eisentraut, A.M., Unger, R.H. : Pancreatic glucagon secretion in normal and diabetic subjects. Amer. J. med. Sci. 257, $415-419$ (1969)

10. Valverde, I., Villanueva, M. L., Lozano, I., DiazFierros, M., Marco, J. : Effect of diazoxide and sulfonylureas on glucagon secretion in normal subjects. Program of the 8 th Annual Meeting of the European Association for the Study of Diabetes, Abstract 282, September, 1972, Madrid

11. Pek, S., Fajans, S. S., Floyd, J.C., Jr., Knopf, R.F., Conn, J.W.: Failure of sulfonylureas to suppress plasma glucagon in man. Diabetes 21, 216-223 (1972)

12. Aguilar-Parada, E., Eisentraut, A.M., Unger, R.H.: Effect of HB-419-induced hypoglycemia on pancreatic glucagon secretion. Horm. Metab. Res. Suppl. 1, 48$50(1969)$

13. Buchanan, K.D., Vance, J.E. Williams, R.H.: Insulin and glucagon release from isolated islets of Langerhans. Effect of enteric factors. Diabetes 18, $381-386(1969)$

14. Chesney, T. McC., Schofield, J.G.: Studies on the secretion of pancreatic glucagon. Diabetes 18,627$632(1969)$

15. Laube, H., Fussgänger, R., Goberna, R., Schroeder, K., Straub, K., Sussman, K., Pfeiffer, E. F.: Effects of tolbutamide on insulin and glucagon secretion of the isolated perfused rat pancreas. Horm. Metab. Res. 3, $238-242(1971)$

16. Iversen, J.: Secretion of immunoreactive insulin and glucagon from the isolated perfused canine pancreas following stimulation with glucose, pancreozymin, arginine and tolbutamide. (Abstract). Excerpta med., IntI. Congr. Ser. 209, 11 (1970)

Dr. J. Marco

Clinica Puerta de Hierro

Universidad Autónoma Madrid

San Martín de Porres 4

Madrid 35

Spain 